First publ. in: Psychotherapy and Psychosomatics 78 (2009), pp. 298-306

\title{
Narrative Exposure Therapy versus Interpersonal Psychotherapy
}

\section{A Pilot Randomized Controlled Trial with Rwandan Genocide Orphans}

\author{
Susanne Schaal ${ }^{a, c}$ Thomas Elbert ${ }^{a, c}$ Frank Neuner ${ }^{b, c}$

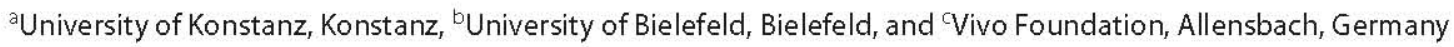

\begin{abstract}
Background: The aim of the present study was to evaluate the efficacy of treatment modules for trauma spectrum disorders in a sample of Rwandan genocide orphans. Methods: Twenty-six orphans (originally 27) who presented with posttraumatic stress disorder (PTSD) at first assessment continued to meet a PTSD DSM-IV diagnosis 6 months after their initial assessment. They were offered participation in a controlled treatment trial. A group adaptation of interpersonal psychotherapy (IPT, $n=14$ ) was compared to individual narrative exposure therapy (NET, $n=12$ ). The last NET session involved guided mourning. Each treatment program consisted of 4 weekly sessions. Main outcome measures were diagnostic status and sym ptoms of PTSD and depression assessed before treatment, at 3 months post-test and at 6 months follow-up using the Clinician-Administered PTSD Scale, Mini-International Neuropsychiatric Interview, and Hamilton Rating Scale. Results: At post-test, there were no significant group differences between NET and IPT on any of the examined outcome measures. At 6-month follow-up, only $25 \%$ of NET, but $71 \%$ of IPT participants still fulfilled PTSD criteria. There was a significant time $x$ treatment in-
\end{abstract}

teraction in the severity of PTSD [Wilks $\Lambda=0.75, F(2,23)=$ 3.93; $p<0.05$ ] and depression symptoms [Wilks' $\Lambda=0.23$, $F(2,23)=3.40 ; p=0.05]$. At follow-up, NET participants were significantly more improved than IPT participants with respect to both the severity of symptoms of PTSD and depression. Conclusions: Individual NET in combination with group-based mourning comprises an effective treatment for traumatized survivors who have to bear the loss of loved ones and have been suffering from symptoms of PTSD and depression.

\section{Introduction}

Many survivors of wars and armed conflicts develop long-term mental disorders. These disorders, which include posttraumatic stress disorder (PTSD), depression, substance abuse, and suicidal behavior, are often accompanied by comorbid symptoms such as social withdrawal, low self-esteem, loss of trust, and feelings of guilt and shame. The application of appropriate interventions for the treatment of traumatic stress in survivors of organized violence, however, remains a challenge and treatment trials in resource-poor countries are rare.

The large numbers of traumatized victims in war-affected areas and limited resources require that any intervention be brief and pragmatic. Narrative exposure ther- 
apy (NET) [1, manual in 2] was developed as a standardized short-term approach to the treatment of the PTSD that results from prolonged, severe, and/or multiple exposure to trauma, conditions that are typical for organized violence. Interpersonal psychotherapy (IPT) is a time-limited therapy that was originally developed for individual treatment of major depression $[3,4]$. IPT is also a feasible and acceptable treatment approach for depressed adolescents, either delivered individually $[5,6]$ or in a group format [7]. There is limited evidence that IPT may also be effective in reducing symptoms of posttraumatic stress [8].

The efficacy of NET $[1,9,10]$ and group IPT $[11,12]$ in resource-poor countries has been demonstrated in randomized controlled studies. Furthermore, 2 case reports $[13,14]$ and an uncontrolled trial $[15]$ in different cultural settings have reported that NET is effective in the treatment of war- and torture-related PTSD in children, adolescents, and adults.

The present study presents a pragmatic trial with the aim of testing the efficacy of 2 promising cost-effective brief procedures for the treatment of PTSD and comorbid depression in a sample of orphaned adolescents and young adults, who experienced severe traumatic stress during the Rwandan genocide in 1994. Previous epidemiological studies examining the enduring mental health effects of this genocide have demonstrated that symptoms of PTSD [16-18] and depression [19] are common among Rwandan genocide survivors, and that treatment modules that target these mental health difficulties are needed.

In the present study, NET and IPT were applied to evaluate the efficacy of both treatment approaches in reducing trauma-related symptoms. In terms of outcomes, we hypothesized that there would be a greater improvement in PTSD diagnosis and posttraumatic stress symptoms for those receiving the individually delivered NET than for those receiving IPT in a group setting. In contrast, we predicted that group IPT would be superior to individual NET in the remission of major depressive episodes (MDE) and depressive symptoms.

\section{Method}

Procedure

The study was conducted in Kigali, the capital of Rwanda, between January 2005 and March 2006. It was approved by the University of Konstanz Ethical Review Board and Rwanda's Ministry of Gender and Family Promotion, Kigali.
The sample consisted of youth living in either child-headed households $(\mathrm{CHH})$ or in orphanages in Kigali. The nongovernmental organization African Evangelistic Enterprise in Kigali referred youth who lived in $\mathrm{CHH}$. Furthermore, we contacted 3 orphanages of different sizes conveniently located in Kigali: the Gisimba Memorial Center orphanage, the Pentecôte Evangélique de la Fraternité en Afrique and the Programme d'Accompagnement des Malades du Sida et des Orphélins Rejetés (PARMARSOR). Orphans who experienced the Rwandan genocide in 1994, who were no older than 18 years during the genocide, and who had lost at least 1 parent during the violence were selected for an epidemiological study (not presented here). The $\mathrm{CHH}$ sample was selected by the African Evangelistic Enterprise following these criteria. In the orphanages, all persons were interviewed that met these criteria and lived in the orphanage during the time of the interview.

Within the framework of the epidemiological survey $(n=118)$, $34 \%$ of the interviewed orphans $(n=40)$ were diagnosed with PTSD according to the DSM-IV (baseline). Of the initial 40, 27 could be relocated and reassessed approximately 6 months later to assess the chronicity and stability of symptoms of PTSD and depression (pre-test, fig. 1). The 13 youth who were not available at pre-test did not differ significantly in demographic variables, trauma exposure, and symptoms of PTSD and depression from those who were available. Of the 27 traumatized youth, only 1 male $\mathrm{CHH}$ orphan no longer fulfilled the PTSD criteria at pretest. The remaining $(\mathrm{n}=26)$ who met the criteria for chronic PTSD were offered participation in the treatment trial. No youth met any of the exclusion criteria, which included mental retardation, psychotic symptoms, or current drug or alcohol abuse. Participants were informed that their participation would be entirely voluntary, and that no monetary compensation would be offered. All persons were willing to participate and provided written informed consent. All participants finished treatment and were reinterviewed 3 months (post-test) and 6 months (follow-up) after therapy. Assessments were carried out by 3 doctoral-level psychologists and 2 graduate students from the University of Konstanz. Interviews were conducted in French, or, with the help of well-trained interpreters, in Kinyarwanda, the national and native language of most Rwandans. Participants were specifically instructed by therapists not to inform the interviewers about their treatment group assignments. In fact, all interviewers were unaware of which treatment condition participants had received. This was confirmed by discussions with the raters after the interviews had been completed.

\section{Treatment}

A group adaptation of IPT $(n=14)$ was compared to individual NET $(\mathrm{n}=12)$. The NET treatment condition comprised 3 individual NET sessions and 1 individual grief session derived from IPT. Because of the large number of losses of loved ones that had been experienced during the genocide, we adapted NET to meet the needs of survivors and integrated a grief module in addition to the standard protocol. During the NET sessions, the participant constructed a detailed chronological account of his/her own biography in cooperation with the counselor. The traumatic experiences were documented by the therapist for later reference and to ensure trauma focus. NET can only be conducted individually as the specific memory of the survivor needs to be activated to allow the integration of emotional, cognitive, physiolog- 
Fig. 1. Flow of participants through the trial. $\mathrm{CHH}=$ Child-headed households; IPT = interpersonal psychotherapy; NET = narrative exposure therapy.

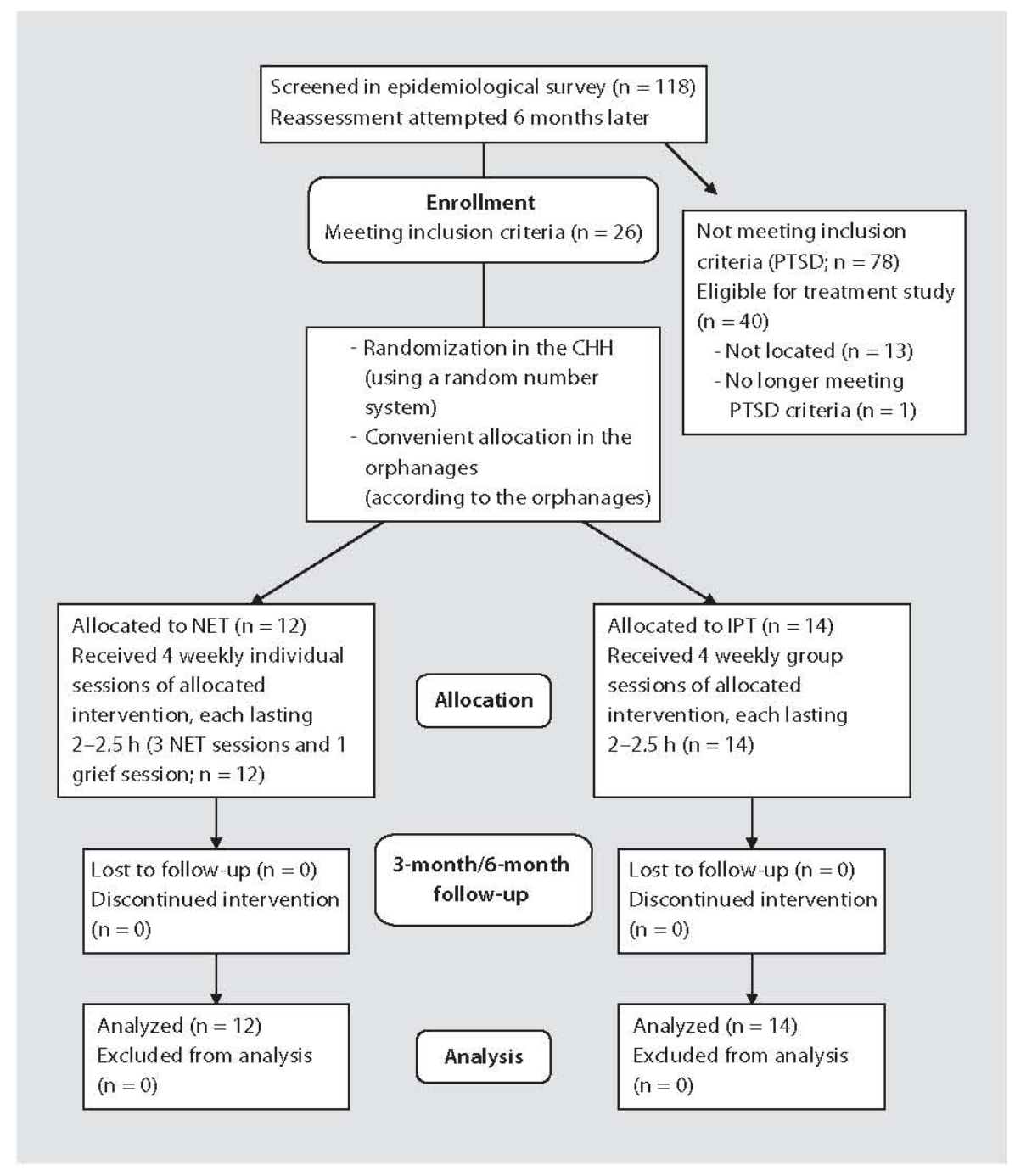

ical, and sensory memories into the context of the past associated with his/her traumatic experiences. During the grief session, the individual talked about someone who had died and expressed associated feelings. This allowed the individual to be exposed to hitherto avoided cues reminding subjects of the deceased, although this was not a specific focus of the guided mourning. At the end of the NET sessions, the participant received a written report of his/her autobiography in French.

Considering the large number of victims in conflict regions like Rwanda, we offered IPT in groups. The group IPT condition comprised 4 single-gender group sessions of 3-4 persons. After establishing the diagnosis of PTSD, depression was placed in an interpersonal context, and the patient's current and past interpersonal relationships were reviewed (interpersonal inventory). Not all participants in the IPT group met the diagnostic criteria for a MDE, but all displayed symptoms of depression. The IPT problem area most relevant to the depression symptomatology was identified and treatment goals were set. After each IPT session, a treatment protocol was registered to guarantee focus on the interpersonal problem areas.
Therapy started in both treatment conditions $1-2$ weeks after the pre-test. One treatment session in each condition lasted between 120 and $150 \mathrm{~min}$. On average, therapists spent the same amount of time in conducting both the treatment conditions. Treatment was carried out by 2 female counselors from the University of Konstanz with previous experience in the applied treatment modules. Treatment was based on manuals that specified precise treatment guidelines. Each of the therapists treated patients in both conditions. Each therapy consisted of 4 weekly sessions. Therapy was conducted with the help of 2 trained interpreters. Weekly meetings were arranged to supervise the quality of treatments. In order to obtain a balanced allocation of the treatment conditions in the $\mathrm{CHH}$ and the orphanages, we formed 2 IPT groups, in the $\mathrm{CHH}$ and the orphanages, respectively. IPT groups from the orphanages were matched according to the availability of single-gender PTSD cases (1 female IPT group in the PARMARSOR and 1 male IPT group in the Gisimba Memorial Center). The remaining youth of the orphanages were assigned to NET. Participants from the $\mathrm{CHH}$ were randomly assigned to either NET or group IPT. After the last therapy session, each $\mathrm{CHH}$ 
participant received compensation of 4,000 Rwandan Francs (about EUR 5) to pay for travel to the treatment location. Participants were unaware before treatment that they would be reimbursed for their travel costs. For the duration of the study, none of the participants received any concurrent psychotherapeutic, psychopharmacological or psychosocial intervention.

\section{Participants}

The mean age of the participants at pre-test was 19.42 years ( $\mathrm{SD}=3.59$, range $14-28$ years). The worst traumatic event had occurred at an average age of $10.23(\mathrm{SD}=4.04)$ years. Ten participants were male and 16 participants were female orphans. The treatment sample comprised 14 youth who lived in orphanages and 12 youth who lived in $\mathrm{CHH}$. The treated orphans were protestant $(\mathrm{n}=18,69 \%)$ or catholic $(\mathrm{n}=8,31 \%)$. Education level attained varied widely with a range of $0-15$ years of school completed (mean $=7.04, \mathrm{SD}=3.29$ ). At pre-test, 11 participants $(42 \%)$ were without any occupation, 9 participants $(35 \%)$ were attending secondary school, 5 participants attended primary school, and 1 orphan was studying at the university. Participants had been exposed (lifetime) to an average of mean $=11.12(\mathrm{SD}=2.42)$ traumatic events. Participants in the 2 treatment conditions did not differ significantly on any of these demographic measures.

\section{Instruments}

Diagnostic status and symptom severity of PTSD were determined using the Clinician-Administered PTSD Scale (CAPS) [20, revised version, 21]. The CAPS is a structured diagnostic interview that indexes the 17 symptoms described by the DSM-IV PTSD criteria. Each symptom is rated on a 5-point scale $(0-4)$ in terms of the frequency and intensity of the symptom in the past week. A severity score (range $0-136$ ) was computed by adding the frequency and intensity scores for each symptom. Cronbach's $\alpha$ on the CAPS severity score for this study was 0.93 .

Additional measures of psychopathology included symptoms of depression using the depression section from the Mini-International Neuropsychiatric Interview (MINI) [22] and depression severity using the Hamilton Depression Rating Scale [23]. The depression score included the sum of the identified symptoms using the MINI and ranged from 0 to $9(\alpha=0.81)$. Scores on the Hamilton Depression Rating Scale ranged from 0 to $63(\alpha=0.87)$. Two additional CAPS items measuring symptoms of guilt were included as secondary outcome measures: trauma-related guilt over acts of commission or omission, and survivor guilt. Frequency and intensity of each of these 2 items were measured on a 5 point scale (0-4). The guilt score was the sum of the severity and frequency score for both CAPS guilt symptoms, and ranges from 0 to 16 .

All measures, except for the demographic questionnaire, were administered at each assessment. In addition, any traumatic events experienced following therapy were recorded during the post-test and follow-up.

\section{Statistical Analysis}

Descriptive data are presented, expressed as frequencies (\%), mean scores, and standard deviations. Between-group differences at pre-test, post-test, and follow-up were analyzed using Fisher's exact tests, Mann-Whitney U tests, independent-sample t tests and analysis of covariance controlling for pre-test levels. The superiority of 1 treatment was identified using parameter estimates.
We conducted repeated-measures analyses of variance (ANOVA) on all outcome measures with assessment (pre-test, post-test, and 6-month follow-up) as the within-subject factor and treatment condition (NET and IPT) as the between-subject factor. Changes in the different outcome measures across the 3 assessment periods (pre-test, post-test and follow-up) were calculated for each condition using Cochran's Q tests, Friedman tests and ANOVA. For significant results, changes within the particular treatment conditions from pre-test to post-test and from pre-test to follow-up were analyzed using binomial tests, paired t tests and Wilcoxon tests. As 2 calculations were carried out for each measure, the significance level was Bonferroni corrected to an $\alpha$ of 0.025 . Effect sizes $\left(\eta^{2}\right)$ were computed for both treatment conditions (pre-test/post-test and pre-test/follow-up). The assumption of homogeneity of variance was tested using the Levene test at a significance level of $p>0.05$. Kolmogorov-Smirnov tests were used to determine normal distribution, and are assured if not otherwise specified. The reported statistical tests are one-tailed.

\section{Results}

Changes in Psychopathology of the 27 PTSD Cases over a Period of 6 Months (Quasi-Waiting List)

There were no significant changes between baseline and pre-test in PTSD diagnosis, in the CAPS severity score, depression score, Hamilton score, MDE, and the guilt score.

Changes in Psychopathology across the Assessment

Periods (Pre-Test, Post-Test, Follow-Up)

Posttraumatic Stress Symptomatology

There were no significant between-group differences in the various measures at pre-test. A significant reduction in the incidence of PTSD diagnosis in the NET group across the assessment periods was found [Cochran's Q (2, $\mathrm{n}=12)=13.56(\mathrm{p}<0.01)]$. The percentage of NET participants meeting DSM-IV criteria for PTSD dropped to $58.3 \%(\mathrm{n}=7$ of 12$)$ at post-test $(\mathrm{p}=0.06)$ and to $25 \%(\mathrm{n}=$ 3 of 12$)$ at follow-up $(\mathrm{p}=0.004)$. In the IPT group, diagnostic criteria for PTSD were met by $71.4 \%(n=10$ of 14$)$ at both assessments (n.s.). At post-test, there was no significant difference in PTSD diagnostic status between the 2 treatment conditions. The difference between the treatment conditions at follow-up, however, was significant $(\mathrm{p}<0.05)$.

Table 1 shows the effects of the 2 treatment conditions on the various outcome variables for each of the pre-test, post-test, and follow-up assessment sessions. The results of an ANOVA revealed a significant main effect for the severity score [Wilks' $\Lambda=0.65, F(2,23)=$ $6.30 ; p<0.01, \eta^{2}=0.35$ ] and a significant time $\times$ treatment interaction for the severity score [Wilks' $\Lambda=0.75$, 
Table 1. Changes in PTSD, depression and guilt symptomatology across the 3 measurement points

\begin{tabular}{llllll}
\hline & Pre-test & Post-test & Follow-up & $\begin{array}{l}\eta^{2} \\
\text { (pre-post) }\end{array}$ & $\begin{array}{l}\eta^{2} \\
\text { (pre-follow-up) }\end{array}$ \\
\hline PTSD diagnosis & & & & \\
$\quad$ NET & $100.00(12)$ & $58.3(7)$ & $25.0(3)$ & - & - \\
$\quad$ IPT & $100.00(14)$ & $71.4(10)$ & $71.4(10)$ & - & - \\
CAPS severity score & & & & & \\
$\quad$ NET & $67.17 \pm 20.10$ & $50.25 \pm 19.20$ & $39.08 \pm 23.37$ & 0.39 & 0.71 \\
IPT & $66.00 \pm 14.10$ & $54.93 \pm 15.60$ & $66.50 \pm 31.93$ & 0.23 & 0.00 \\
MDE & $66.70(8)$ & $50.00(6)$ & $16.70(2)$ & - & - \\
$\quad$ NET & $92.90(13)$ & $50.00(7)$ & $50.00(7)$ & - & - \\
$\quad$ IPT & $6.00 \pm 2.52$ & $5.00 \pm 2.00$ & $2.75 \pm 2.56$ & 0.12 & 0.52 \\
MINI depression score & $6.57 \pm 2.03$ & $4.79 \pm 2.75$ & $4.86 \pm 2.74$ & 0.28 & 0.41 \\
$\quad$ NET & & & & & \\
IPT & $26.42 \pm 7.97$ & $19.00 \pm 8.58$ & $11.42 \pm 8.61$ & 0.45 & 0.75 \\
Hamilton score & $28.43 \pm 7.18$ & $21.50 \pm 7.34$ & $19.50 \pm 8.24$ & 0.35 & 0.43 \\
$\quad$ NET & & & & & \\
$\quad$ IPT & $6.75 \pm 3.31$ & $2.92 \pm 4.41$ & $3.00 \pm 4.41$ & 0.40 & 0.71 \\
Guilt score & $4.57 \pm 2.17$ & $4.21 \pm 3.58$ & $5.14 \pm 4.57$ & 0.02 & 0.01 \\
$\quad$ NET & & & & & \\
$\quad$ IPT & &
\end{tabular}

Figures are percentages with numbers of participants in parentheses or mean \pm standard deviation.

$\left.\mathrm{F}(2,23)=3.93 ; \mathrm{p}<0.05, \eta^{2}=0.26\right]$. The groups did not differ at post-test, but at follow-up NET participants scored significantly lower on the severity score than IPT participants when controlling for pre-test scores (table 2; fig. 2).

Repeated-measures ANOVA for the NET group showed a significant time effect for the severity score [Wilks' $\left.\Lambda=0.28, \mathrm{~F}(2,10)=12.64 ; \mathrm{p}<0.01, \eta^{2}=0.72\right]$. The mean of the severity score significantly dropped from pre- to post-test $[\mathrm{t}(11)=2.64, \mathrm{p}=0.02]$ and from pre-test to follow-up [t(11) $=5.17, \mathrm{p}<0.001]$. Repeated-measures ANOVA for the IPT condition showed no significant time effect for the severity score.

Table 1 and figure 2 show that NET participants continued to show further improvements in posttraumatic stress symptoms from post-test to follow-up. Orphans in the IPT group did not maintain their post-test results. At post-test and at follow-up, NET participants demonstrated larger effect sizes on PTSD and depression measures compared to IPT participants.

Depression Symptomatology

There were no significant between-group differences at pre-test on measures of depression (MDE, depression score, Hamilton score; fig. 2).
Table 2. Between-group differences in posttraumatic stress symptomatology and depression symptomatology at follow-up

\begin{tabular}{lll}
\hline Measures & F statistics & Parameter estimate $^{1}$ \\
\hline CAPS severity score & $\mathrm{F}(1,23)=7.68^{* *}$ & $\begin{array}{l}\mathrm{B}=-28.28, \\
\mathrm{t}(23)=-2.77^{* *}\end{array}$ \\
MINI depression score & $\mathrm{F}(1,23)=3.47^{*}$ & $\begin{array}{l}\mathrm{B}=-1.83, \\
\mathrm{t}(23)=-1.86^{*}\end{array}$ \\
Hamilton score & $\mathrm{F}(1,23)=5.20^{*}$ & $\begin{array}{l}\mathrm{B}=-7.57, \\
\mathrm{t}(23)=-2.28^{*}\end{array}$
\end{tabular}

Results of a covariance analysis.

${ }^{*} \mathrm{p}<0.05$; ${ }^{* * *} \mathrm{p}<0.01$.

${ }^{1}$ Regression coefficient B and test statistic; category of reference: NET.

Participants in both NET and IPT treatment conditions showed a significant change in diagnostic status of MDE across the 3 measurement points [Cochran's Q (2, $\mathrm{n}=12)=6.22, \mathrm{p}<0.05$, Cochran's $\mathrm{Q}(2, \mathrm{n}=14)=9.0$, $p<0.05$, respectively]. The presence of an MDE in orphans receiving NET declined from $66.7 \%(\mathrm{n}=8)$ at pretest to $50 \%(n=6)$ at post-test (n.s.) to $16.7 \%(n=2)$ at 


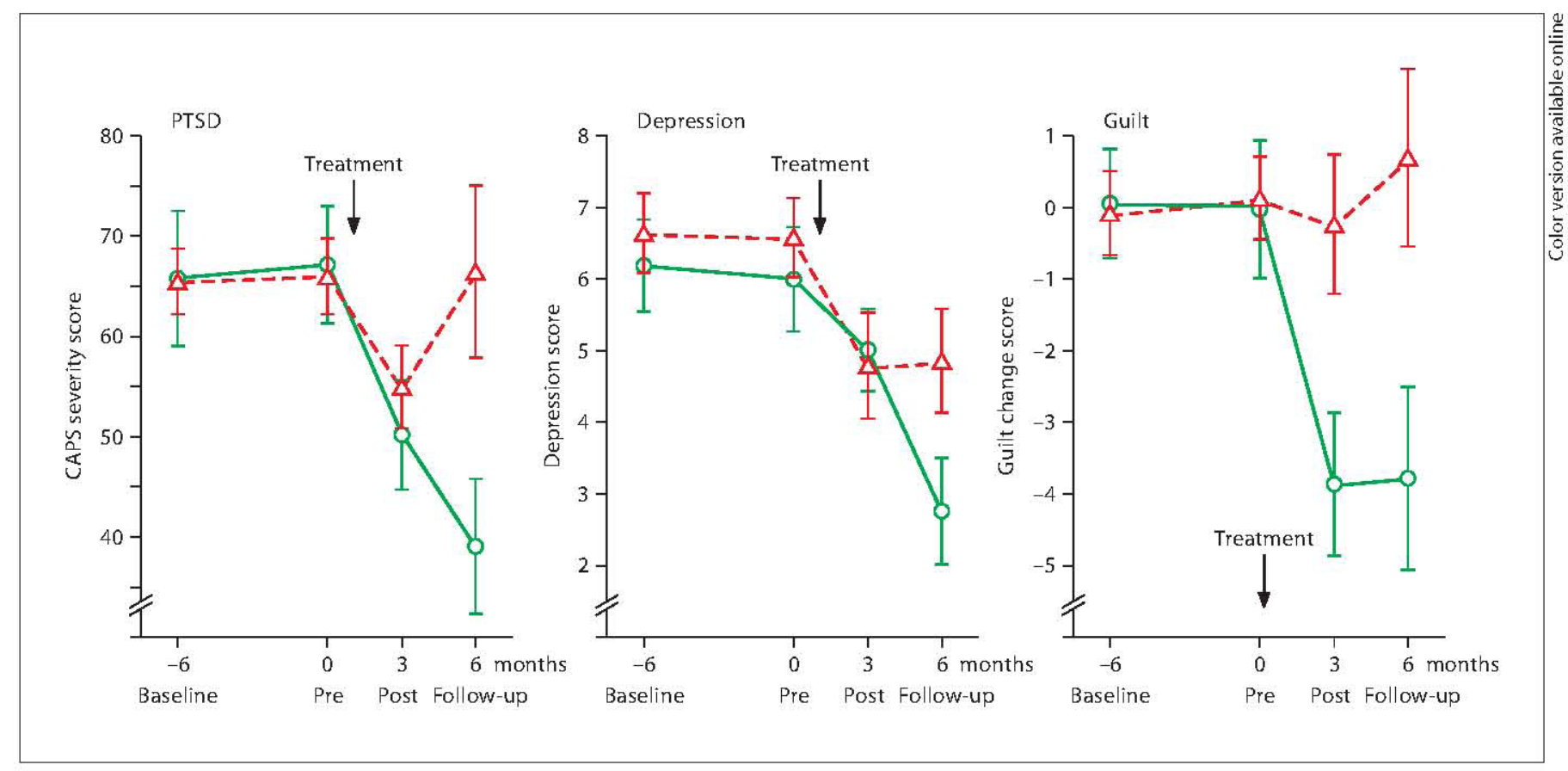

Fig. 2. Time course (baseline to follow-up) for CAPS severity score, depression score, and change in guilt for the 2 treatment groups (means $\pm \mathrm{SE}$ ). $\mathrm{O}=\mathrm{NET} ; \triangle=\mathrm{IPT}$.

follow-up $(\mathrm{p}=0.07)$. IPT participants showed a remission of MDE from $92.9 \%(n=13)$ at pre-test to $50 \%(n=7)$ at post-test and follow-up ( $\mathrm{p}=0.03)$.

Repeated-measures ANOVA showed a significant main effect for the depression score [Wilks' $\Lambda=0.51$, $\left.F(2,23)=10.90 ; p<0.001, \eta^{2}=0.49\right]$ and the Hamilton score [Wilks' $\Lambda=0.39, \mathrm{~F}(2,23)=18.06 ; \mathrm{p}<0.001, \eta^{2}=$ 0.61 , and an interaction between treatment and time for the depression score [Wilks' $\Lambda=0.23, \mathrm{~F}(2,23)=3.40 ; \mathrm{p}=$ $\left.0.05, \eta^{2}=0.23\right]$. At post-test, there were no significant between-group differences in depression score or Hamilton score. However, the 2 treatment conditions differed significantly on these scores at follow-up. For both measures, the NET group achieved a significantly greater symptom reduction (table 2).

In the NET group the repeated-measures ANOVA revealed a significant change in the depression score and Hamilton score across time [Wilks' $\Lambda=0.57, \mathrm{~F}(2,10)=$ $6.55 ; p<0.05, \eta^{2}=0.57$, Wilks' $\Lambda=0.25, F(2,10)=14.90$; $\mathrm{p}<0.01, \eta^{2}=0.75$, respectively]. Depression score significantly changed from pre-test to follow-up [t(11) = $3.46, \mathrm{p}=0.005]$. The Hamilton score displayed a significant change from pre-test to post-test that was maintained at follow-up $[\mathrm{t}(11)=2.99, \mathrm{p}=0.02, \mathrm{t}(11)=5.73, \mathrm{p}<$ 0.001 , respectively].
Similarly, analyses of the IPT group revealed a significant change in the depression score and the Hamilton score across the assessment periods [Wilks' $\Lambda=0.59$, $\mathrm{F}(2,12)=4.22 ; \mathrm{p}<0.05, \eta^{2}=0.41$, Wilks' $\Lambda=0.55$, $F(2,12)=4.91 ; p<0.05, \eta^{2}=0.45$, respectively]. The change in the depression score in the IPT group from preto post-test was marginally significant $[\mathrm{t}(13)=2.27, \mathrm{p}=$ $0.04]$ and from pre-test to follow-up significant $[\mathrm{t}(13)=$ $3.02, p=0.01]$. The Hamilton score revealed a significant change across both measurement points $[\mathrm{t}(13)=2.67, \mathrm{p}=$ $0.02, \mathrm{t}(13)=3.16, \mathrm{p}=0.01$, respectively]. Figure 2 illustrates the changes in the depression score in both treatment conditions over the measurement points, including the scores of the initial assessment (baseline).

Guilt Symptomatology

At pre-test, there were no significant mean differences in guilt scores between the 2 treatment conditions. The results of an ANOVA revealed a significant main effect for the guilt score [Wilks' $\Lambda=0.70, F(2,23)=4.93$; $<<$ $\left.0.05, \eta^{2}=0.30\right]$ and a significant time $\times$ treatment interaction [Wilks' $\Lambda=0.73, F(2,23)=4.31 ; \mathrm{p}<0.05, \eta^{2}=0.27$ ] (fig. 2).

In the NET group, the guilt score changed significantly across measurement points [Friedman $\chi^{2}(2, n=12)=$ 
$11.23(\mathrm{p}<0.01)$ ]. The mean score decreased from 6.75 $(\mathrm{SD}=3.31)$ at pre-test to $2.92(\mathrm{SD}=4.41)$ at post-test $(\mathrm{z}=$ $-2.81, \mathrm{p}=0.005)$. This improvement in guilt symptom level was maintained at follow-up $[$ mean $=3.00$ (SD $=$ 4.41), $\mathrm{z}=-2.09, \mathrm{p}=0.036$ ]. IPT participants did not show any significant changes in the guilt-score [pre-test: mean $=4.57, \mathrm{SD}=2.17$, post-test: mean $=4.21, \mathrm{SD}=3.58$, follow-up: mean $=5.14, \mathrm{SD}=4.57]$. At post-test, there was a significant between-group difference $[\mathrm{F}(1,23)=3.44$, $\mathrm{p}<0.05$ ], with NET participants having a lower guilt score at post-test, while controlling for pre-test scores $[\mathrm{t}(23)=-1.85, \mathrm{p}<0.05]$. At follow-up, there was no significant difference.

\section{Discussion}

We monitored trauma-related symptoms (PTSD, depression, and guilt cognitions) over a period of 6 months (from baseline to pre-test) to measure the stability of PTSD symptoms in a sample of Rwandan orphans who met DSM-IV criteria of PTSD at the initial assessment. Subsequently, we tested the efficacy of brief versions of individual NET and group IPT in alleviating traumaspectrum disorders in a sample of 26 Rwandan genocide orphans who fulfilled PTSD criteria. We hypothesized greater improvements in diagnostic status and symptom level of PTSD in the NET group, and greater improvements in diagnostic status and symptom level of depression in the IPT group, at both measurement points (post-test and follow-up). During the 6-month baseline period, there was no improvement in symptoms of psychopathology. All but 1 respondent met the PTSD criteria at the second assessment. Simply monitoring symptomatology did not alter the condition. While there may be fluctuations in psychopathological symptoms, an enduring improvement in psychological well-being may require effective psychotherapeutic intervention.

The hypothesis that the NET treatment would be superior to IPT in reducing both diagnostic status and the severity of PTSD symptoms at post-test and follow-up was supported. At post-test, NET participants showed a significant reduction in the severity of PTSD symptoms, although a similar improvement was found in the IPT group. At 6-month follow-up, however, indications of posttraumatic stress had further resolved in NET participants, whereas symptoms had remained or even reappeared in IPT participants. Only $25 \%$ of the NET participants still met diagnostic criteria at follow-up. In con- trast, in the IPT group, the percentage of participants meeting PTSD diagnosis criteria remained at a high level of $71 \%$.

The results of the present study do not support the hypothesis that IPT is superior to NET in ameliorating symptoms of depression at post-test or follow-up. While there were no between-group differences in depression measures at post-test, the NET treatment condition showed significantly greater improvements than the IPT group at follow-up. However, it should be noted that both treatment conditions led to a significant reduction in depressive symptoms at follow-up. NET, but not IPT, produced a remediation in guilt cognitions.

The improvement in PTSD diagnosis following NET treatment found in the present study is consistent with the results of the studies by Neuner et al. $[1,10]$. Several previous studies have also shown that exposure-based interventions are effective in reducing PTSD symptoms [e.g. 24-28]. Exposure to and processing of the traumatic memories seems a necessary treatment component for the lasting remission of PTSD. The present study shows that even a small number of NET sessions in combination with guided mourning can lead to a significant reduction in PTSD symptoms [compare 13-15]. Whereas the NET group showed a continuous decline in PTSD symptoms, the IPT group showed only a short-term decline that did not persist in the long term. It is clear that 4 IPT sessions, even ones of a long duration as used here, were not sufficient for these severely traumatized victims. However, a longer treatment time might have led to a more enduring improvement.

The efficacy of group IPT has been reported in other studies for the treatment of adults $[11,12]$, as well as in a pilot study with adolescents [7]. According to Mufson et al. [7], group IPT seems especially suited to treatment of adolescents, as they are willing to accept the influence of adults and yet are also increasingly looking to their peers for advice and help. Even though IPT participants did not display a continuing decline in depressive symptoms from post-test to follow-up, it is remarkable that they still maintained their post-test results. The stability of symptoms during baseline would argue against a simple temporal dynamic.

The IPT intervention that has been developed for the treatment of depression seems especially appealing for or phans as they have comparable problems to each other. Robertson et al. [29] concluded that it might be advantageous if IPT group participants present with the same problem areas, since interactions between group members are enhanced and a positive group process is initi- 
ated. For orphans, presenting issues such as mistrust, low self-esteem, discomfort expressing feelings, as well as isolation and loneliness play a central role. These aspects can easily be targeted in a group setting. Group IPT seems also well suited to this orphaned sample, since all participants had experienced similar events during the genocide. Specifically, all had lost their parents and were coping with the problem area of role transition. This allowed the group members to benefit from the exploration and discussion of others' problems in addition to their own. It is probable that the similar experiences of the orphans increased interest, understanding and openness within the group.

In contrast to the IPT group, the NET participants continued to show a decline in depressive symptomatology over time. There are a number of studies that demonstrate that exposure therapy $[24,25,27,30]$, and in particular NET [15], leads to reductions in depression symptoms, and that such improvements are still maintained 9-12 months after therapy $[15,24,25]$.

Since the NET condition comprised 2 components (3 $\mathrm{NET}+1$ grief session), we were unable to determine the relative importance of each of these components in the reduction of symptoms of PTSD and depression. It is possible that the reduction in PTSD symptoms led to an improvement in depression symptoms. On the other hand, it is possible that the 1 IPT session (grief module), in conjunction with NET, had the decisive positive influence on the reduction in depression symptoms.

The reduction in guilt cognitions in the NET condition reflects the findings from Resick et al. [31] that exposure may shift guilt cognitions. It seems that the chronological report of the traumatic events led to a cognitive reorganization. Cognitive restructuring may not be necessary for the reduction in guilt cognitions. Also, the findings of Marks et al. [32] demonstrate that exposure alone produced similar marked improvements in guilt cognitions compared to cognitive restructuring or the combination of both.

The present study has a number of limitations. The sample size was modest, a factor that does not lead to confident estimates of effect size. The study did not include a no-treatment group or a wait list control group. However, the long baseline demonstrated that mere assessment did not alter the mental suffering. We did not test inter-rater reliability as all raters were clinical experts with long-term diagnostic experience, and all had been trained in the same clinical setting. Additionally, all interviewers carried out interviews for both treatment conditions. In the present pragmatic trial, an indi- vidual trauma-focused therapy and a group non-trauma-focused therapy were applied. We used NET and IPT as these standardized short-term approaches target the most common trauma-related disorders of PTSD and depression. We were aware that the 2 treatment modules differed with respect to 2 main characteristics, i.e. treatment focus (past vs. present) as well as mode of treatment (individual vs. group). However, as we aimed at a pragmatic comparative evaluation of the approaches in a preliminary trial, we decided to offer each approach in the most promising format. Due to the high number of losses experienced by Rwandans, the original NET approach was complemented by a grief session derived from the standardized IPT manual. We are not able to judge to what extent the individual treatment format, the exposure component, the grief session, or the combination of these factors in the NET protocol contributed to the superiority and success of this treatment approach.

Despite these limitations, we demonstrated that NET, in combination with a grief module, is an effective treatment approach for traumatized survivors who are simultaneously affected by PTSD, symptoms of depression, and the loss of loved ones. Substantial improvement occurred within a relatively small number of sessions. Our sample consisted of people with chronic PTSD, and there were no dropouts; thus, the chronicity of symptoms observed during baseline and the marked drop from pretest to follow-up were unlikely to be due to the mere passage of time. A treatment combination of NET and guided mourning may improve the mental well-being of many victims of organized violence, as trauma and loss often coincide in this population. Our findings need to be replicated, something that should be feasible as we used treatment modules derived from standardized treatment manuals.

The large number of traumatized youth in Rwanda and limited resources require that any intervention be brief and pragmatic and easy for local personnel to learn, even with little or no previous access to medical or psychological education. Studies have been completed in resource-poor countries (for example Uganda) that have demonstrated the feasibility of the approach to train locals in NET [10,33] or IPT [11]. If treatment is applied by local personnel, a large number of survivors can potentially be reached. Additionally, the treatment of traumatized survivors may eventually break the cycle of violence because such an intervention includes the facilitation of forgiveness and reconciliation within the community [17]. 


\section{Acknowledgments}

We would like to thank Dr. Patience Onyut, Maria Roth, Nadja Jacob and Verena Ertl for support in data collection and treatment, and Michael Coles for editing and helpful comments.

We greatly acknowledge the support, advice and expertise of Prof. Brigitte Rockstroh, Joseph Nyamutera, Gilbert Hategekimana, Jean-Paul Mutabaruka, James Haganza, and Dr. Maggie Schau- er as well as the African Evangelistic Enterprise, the Gisimba Memorial Center orphanage, the Pentecôte Evangélique de la Fraternité en Afrique and the PARMARSOR orphanage in Kigali.

We would further like to extend our thanks to all the youth, and the many others who have supported our work with great enthusiasm, trust, and openness.

This research was funded by the Falk v. Reichenbach Foundation and the Deutsche Forschungsgemeinschaft.

\section{References}

1 Neuner F, Schauer M, Klaschik C, Elbert T, Karunakara U, Elbert T: A comparison of narrative exposure therapy, supportive counseling, and psychoeducation for treating posttraumatic stress disorder in an African refugee settlement. J Consult Clin Psychol 2004;72: 579-587.

2 Schauer M, Neuner F, Elbert T: Narrative Exposure Therapy: A Short-Term Intervention for Traumatic Stress Disorders after War, Terror, or Torture. Ashland, Hogrefe \& Huber, 2005.

3 Klerman GL, Weissman MM, Rounsaville BJ, Chevron ES: Interpersonal Psychotherapy of Depression. New York, Basic Books, 1984, pp $73-182$.

4 Schramm E: Interpersonelle Psychotherapie. Stuttgart, Schattauer, 1996.

5 Mufson L, Pollack Dorta K, Wickramaratne P, Nomura Y, Olfson M, Weissman MM: A randomized effectiveness trial of interpersonal psychotherapy for depressed adolescents. Arch Gen Psychiatry 2004;61:577-584.

6 Mufson L, Weissman MM, Moreau D, Garfinkel R: Efficacy of interpersonal psychotherapy for depressed adolescents. Arch Gen Psychiatry 1999;56:573-579.

7 Mufson L, Gallagher T, Pollack Dorta K, Young JF: A group adaptation of Interpersonal Psychotherapy for depressed adolescents. Am J Psychother 2004;58:220-237.

8 Bleiberg KL, Markowitz JC: A Pilot Study of interpersonal psychotherapy for posttraumatic stress disorder. Am J Psychiatry 2005; 162:181-183.

9 Bichescu D, Neuner F, Schauer M, Elbert T: Narrative exposure therapy of political imprisonment-related chronic trauma-spectrum disorders. Behav Res Ther 2007;45:2212-2220.

10 Neuner F, Onyut P, Ertl V, Schauer E, Odenwald M, Elbert T: Treatment of posttraumatic stress disorder by trained lay counsellors in an African refugee settlement - a randomized controlled dissemination trial. J Consult Clin Psychol 2008;76:686-694.

11 Bolton P, Bass J, Neugebauer R, Verdeli H, Clougherty KF, Wickramaratne $\mathrm{P}$, Speelman L, Ndogoni L, Weissman M: Group interpersonal psychotherapy for depression in rural Uganda: a randomized controlled trial. JAMA 2003;289:3117-3124.

12 Verdeli H, Clougherty K, Bolton P, Speelman L, Ndogoni L, Bass J, Neugebauer R, Weissman MM: Adapting a group interpersonal psychotherapy for a developing country: ex- perience in rural Uganda. World Psychiatry 2003;2:114-120.

13 Neuner F, Schauer M, Elbert T, Roth WT: A narrative exposure treatment as intervention in a refugee camp: a case report. J Behav $\mathrm{Cog}$ Psychother 2002:30:205-209.

14 Schauer E, Neuner F, Elbert T, Ertl V, Onyut LP, Odenwald M, Schauer M: Narrative exposure therapy in children: a case study. Intervention $2004: 2: 18-32$.

15 Onyut PL, Neuner F, Schauer E, Ertl V, Odenwald M, Schauer M, Elbert T: Narrative exposure therapy as a treatment for child war survivors with posttraumatic stress disorder: two case reports and a pilot study in an African refugee settlement. BMC Psychiatry 2005; 5:7.

16 Gishoma D: Analyse de la situation du traumatisme psychique dans les ménages dirigés par les enfants au Rwanda (mémoire). Butare Université nationale du Rwanda: faculté d'éducation, 2005.

17 Pham PN, Weinstein HM, Longman T: TraumaandPTSDinRwanda.JAMA 2004;292:602612.

18 Schaal S, Elbert T: Ten years after the genocide: trauma confrontation and posttraumatic stress in Rwandan adolescents. J Trauma Stress 2006;19:95-105.

19 Bolton P, Neugebauer R, Ndogoni L: Prevalence of depression in rural Rwanda based on symptom and functional criteria. J Nerv Ment Dis 2002;190:631-637.

20 Blake DD, Weathers FW, Nagy LM, Kaloupek DG, Gusman FD, Charney DS, Keane T: The development of a Clinician-Administered PTSD Scale. J Trauma Stress 1995;8:75-90.

21 Blake DD, Weathers FW, Nagy LM, Kaloupek DG, Klauminzer G, Charney DS, et al: Clinician-Administered PTSD Scale for DSM-IV. National Center for Posttraumatic Stress Disorder. Boston VA Medical Center, West Haven VA Medical Center, 1998.

22 Sheehan DV, Lecrubier Y, Sheehan H, Amorim P, Janavs I, Weiller E, Hergueta T, Baker R, Dunbar GC: The MINI-International Neuropsychiatric Interview (MINI): the development and validation of a structured diagnostic psychiatric interview for DSM-IV and ICD-10. J Clin Psychiatry 1998:59:22-33.

23 Hamilton M: Development of a rating scale for primary depressive illness. Br J Soc Clin Psychol 1967;6:278-296.

24 Foa EB, Dancu CV, Hembree EA, Jaycox LH, Meadows EA, Street GP: A comparison of exposure therapy, stress inoculation training, and their combination for reducing posttraumatic stress disorder in female assault victims. J Clin Psychol 1999;67:194-200.

25 Foa EB, Hembree EA, Cahill SP, Rauch SAM, Riggs DS, Feeny NC, Yadin E: Randomized trial of prolonged exposure for posttraumatic stress disorder with and without cognitive restructuring: outcome at academic and community clinics. I Consult Clin Psychol 2005;73:953-964.

26 Tarrier N, Pilgrim H, Sommerfield C, Faragher B, Reynolds M, Graham E, Barrowclough C: A randomized trial of cognitive therapy and imaginal exposure in the treatment of chronic posttraumatic stress disorder. J Consult Clin Psychol 1999;67:13-18.

27 Taylor S, Thordarson DS, Fedoroff IC, Maxfield L, Lovell K, Ogrodniczuk J: Comparative efficacy, speed, and adverse effects of three PTSD treatments: exposure therapy, EMDR, and relaxation training. J Consult Clin Psychol 2003;71:330-338.

28 Foa EB, Rothbaum BO, Riggs DS, MurdockTB: Treatment of posttraumatic stress disorder in rape victims: a comparison between cognitivebehavioral procedures and counseling. J Consult Clin Psychol 1991;59:715-723.

29 Robertson M, Rushton PJ, Bartrum D, Ray R: group-based interpersonal psychotherapy for posttraumatic stress disorder: theoretical and clinical aspects. Int $\mathrm{J}$ Group Psychother 2004:54:145-175.

30 Stapleton IA, Taylor S, Asmundson GJG: Effects of three PTSD treatments on anger and guilt: exposure therapy, eye movement desensitization and reprocessing, and relaxation training. J Trauma Stress 2006;19:19-28.

31 Resick PA, Nishith P, Weaver TL, Astin MC, Feuer CA: A comparison of cognitive-processing therapy with prolonged exposure and a waiting condition for the treatment of chronic posttraumatic stress disorder in female rape victims. I Consult Clin Psychol 2002;70:867-879.

32 Marks I, Lovell K, Noshirvani H, Livanou M, Thrasher S: Treatment of posttraumatic stress disorder by exposure and/or cognitive restructuring: a controlled study. Arch Gen Psychiatry 1998;55:317-325.

33 Onyut PL, Neuner F, Schauer E, Ertl V, Odenwald M, Schauer M, Elbert T: The Nakivale Camp Mental Health Project: building local competency for psychological assistance to traumatised refugees. Intervention 2004;2: 90-107. 